\title{
OVARIAN WEIGHT AND OVARIAN COMPENSATORY HYPERTROPHY IN THE RAT AS AFFECTED BY DURATION OF UNDERFEEDING
}

\author{
B. E. HOWLAND \\ Department of Oral Biology, The University of Manitoba, Winnipeg 3, Canada
}

(Received 21st September 1971, accepted 6th October 1971)

The detrimental effects of underfeeding on ovarian function in the female rat are characterized by cessation of oestrous cycles and ovarian atrophy (Rinaldini 1949; Piacsek \& Meites, 1967). These effects appear to be the result of impaired release of gonadotrophins due to deficient secretion of hypothalamic gonadotrophin releasing factors (Piacsek \& Meites, 1967). Decreased basal levels of plasma LH have been demonstrated in female rats after 20 days of restricted feed intake (Howland \& Ibrahim, 1971). Not only is gonadotrophin secretion altered in intact animals by underfeeding, but the ability of the hypothalamus and pituitary gland to respond to hemiovariectomy is also impaired. When hemiovariectomy was performed after 10 days of underfeeding, hypertrophy of the remaining ovary did not occur during the ensuing 10 days (Howland, 1971). The present study was undertaken to determine the effect of duration of underfeeding both on gonadotrophin secretion, as indicated by ovarian weight, and on hypothalamic-pituitary responsiveness to changes in ovarian steroid level, as indicated by ovarian compensatory hypertrophy.

Adult, female, Sprague-Dawley rats (2 to 4 months old) were allowed unrestricted access to Purina Laboratory Chow (full-fed animals) or were allowed $50 \%$ of their unrestricted consumption as measured during a 3-day pre-experimental period (underfed animals). The animals were individually caged in a light-controlled (12 hr light $12 \mathrm{hr}$ dark) and temperature-controlled $\left(74 \pm 1^{\circ} \mathrm{F}\right)$ room. In hemiovariectomized groups, the left ovary was removed at laparotomy and the remaining right ovary was removed at autopsy 10 days later. In two groups where compensatory hypertrophy was not studied, the left ovaries were obtained at autopsy.

The effect of duration of underfeeding on ovarian weight and ovarian compensatory hypertrophy is shown in Text-fig. 1. Left ovary weights in intact rats showed a progressive decline from a mean of $43.6 \mathrm{mg}$ on Day 0 (first day of feed treatment) to a mean of $15.0 \mathrm{mg}$ on Day 34 of underfeeding. Full-fed rats responded to hemiovariectomy with the expected compensatory increase in the weight of the remaining ovary. Ovarian compensatory hypertrophy in underfed rats was evident when hemiovariectomy was performed on Day 0 of underfeeding but the degree of response appeared to be less than that observed in full-fed rats. A compensatory increase in ovarian weight was no longer evident following hemiovariectomy on Day 10 of underfeeding and by 


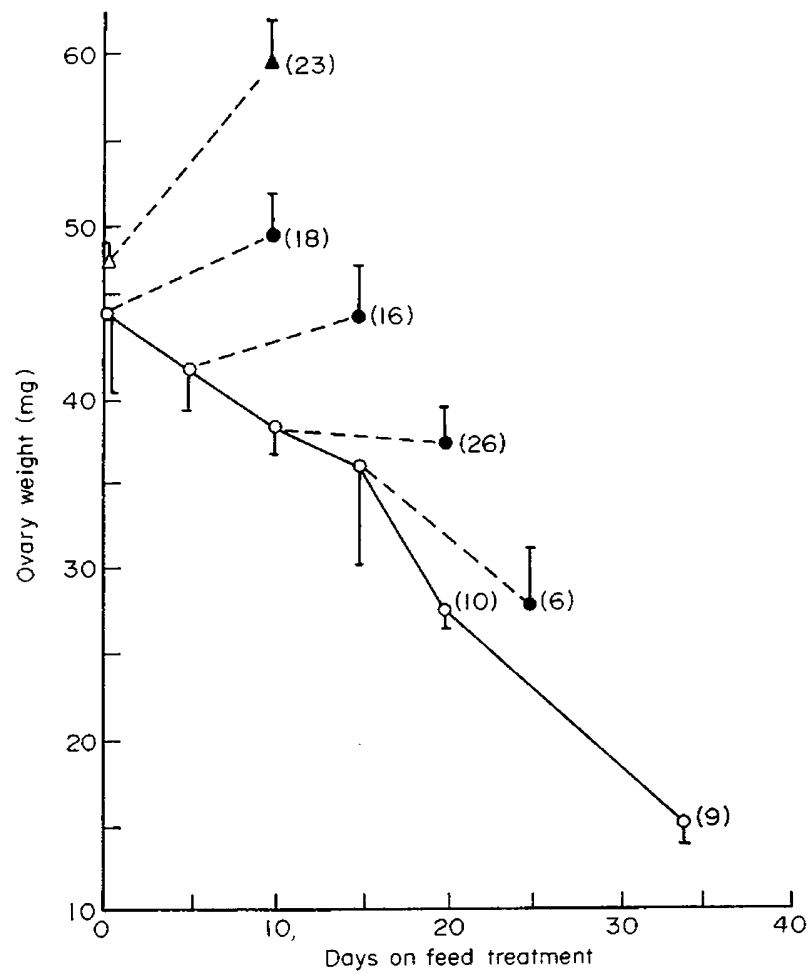

TEXT-FIG. 1. Changes in left ovarian weight $(0-0)$ with increased duration of underfeeding and ovarian compensatory hypertrophy in full-fed $(\Delta-\Delta)$ and underfed $(0-0)$ rats. For each broken line, the open symbol indicates the mean weight of left ovaries removed at laparotomy while the solid symbol indicates the mean weight of the remaining right ovaries for the same animals 10 days later. Standard errors are shown by vertical bars. Numbers of animals are in parentheses.

Day 15 of underfeeding, hemiovariectomy was followed by a decline in the weight of the remaining ovary at a rate approaching that of intact animals.

These data provide indirect evidence that pituitary secretion of gonadotrophins in intact rats may begin to decline as soon as feed restriction is imposed. Furthermore, the ability of the hypothalamic-pituitary complex to respond to a reduction in circulating ovarian steroids, although still evident during the first 10 days of underfeeding, rapidly disappears with increased duration of feed restriction. In spite of the fact that the oestrous cycles do not cease until 14 to 21 days after the beginning of $50 \%$ feed restriction (Piacsek \& Meites, 1967), pituitary failure can be demonstrated much earlier.

This work was supported by M.R.C. Canada grant MA-4454 and a grant from the National Research Council of Canada (A-6248).

\section{REFERENCES}

Howland, B. E. (1971) Effect of restricted feed intake on ovarian compensatory hypertrophy in the rat. F. Anim. Sci. 33, 83. 
Howland, B. E. \& Ibrahim, E. A. (1971) Effect of level of feeding on pituitary and plasma LH concentration in the female rat. (Abstract). Can. F. Anim. Sci. (In press).

Pracsek, B. E. \& Mertes, J. (1967) Reinitiation of gonadotropin release in underfed rats by constant light or epinephrine. Endocrinology, 81, 535 .

Rinaldint, L. M. (1949) Effect of chronic inanition on the gonadotrophic content of the pituitary gland. F. Endocr. 6, 54. 